\title{
Congenital insensitivity to pain: How should anesthesia be managed?
}

\author{
Özlem Özmete, Mesut Şener, Çağla Bali, Esra Çalışkan, Anış Arıboğan \\ Department of Anesthesiology and Reanimation, Başkent University Faculty of Medicine, Adana, Turkey. E-mail: \\ ozlemyilma@yahoo.com \\ Received: 24th May 2016, Accepted: 22nd July 2016
}

SUMMARY: Özmete Ö, Şener M, Bali Ç, Çalışkan E, Arıboğan A. Congenital insensitivity to pain: How should anesthesia be managed? Turk J Pediatr 2017; 59: 87-89.

Congenital insensitivity to pain syndrome is a rare, sensorial and autonomic neuropathy characterized by unexplained fever, insensitivity to pain and anhidrosis. Patients may require anesthesia even for minor surgical procedures due to mental retardation and trauma arising from self- mutilating behavior.

A child diagnosed with congenital insensitivity to pain syndrome was scheduled for gastric endoscopy under sedation due to suspected ingestion of a household cleaning disinfectant. Deep sedation was achieved, and spontaneous respiration was maintained. We did not encounter any complications.

There is limited data regarding the safe anesthesia management in these patients because of the rarity of the disease. Therefore, we think that more clinical experience, case reports and studies are needed to establish the appropriate anesthesia management.

Key words: congenital insensitivity to pain, pediatric patient, sedation, general anesthesia.

Pain is a messenger defense mechanism which expresses any damage or deterioration in the body. The organism protects itself from harmful stimuli due to this sensation. This mechanism is broken in congenital insensitivity to pain with anhidrosis (CIPA). It is classified within a group of diseases called hereditary sensory and autonomic neuropathy (HSAN). ${ }^{1}$ There are five subtypes of this disease under the title of HSAN. It may also be observed in different sensations as well as the lack of pain perception in each of these disease entities. The type of HSAN which the patient belongs requires peripheral nerve biopsy and detailed neurological evaluation. ${ }^{2}$

Congenital insensitivity to pain with anhidrosis (CIPA) is an extremely rare autosomal recessive autonomic neuropathy of early childhood ${ }^{1}$. It has a poor prognosis, with $43 \%$ of affected patients dying as a result of hyperthermia and sepsis within the first 3 years. Clinically it is characterized by systemic anhidrosis, pain and heat insensitivity, recurrent and unexplained fever and mental retardation of varying degrees.
Behavior of self-injury, mutilation and increase in body temperature can be seen in these patients. ${ }^{1}$

\section{Case Report}

A 7-year-old $20 \mathrm{~kg}$ male patient diagnosed with CIPA was scheduled for endoscopy because of suspected ingestion of a household cleaning disinfectant. It was learned from the history of the patient that CIPA was diagnosed when he was fifteen months old as the patient went to the hospital suffering from frequent fever, painless injections and giving no reactions to the injuries and burns. In preoperative assessment, he was noted to have mental retardation as well as old burns and traumatic scars in upper and lower extremities (Fig. $1)$. Although the patient was suspected of drinking a household cleaning disinfectant, it was observed that the swallowing reflex was painless. The patient had no history of previous surgical procedures and his preoperative laboratory values were within normal limits. The fasting time of the patient was 6 hours; 
therefore, an endoscopic intervention was planned under sedation. The patient was taken into the operating room after intravenous administration of $2 \mathrm{mg}$ of midazolam, $0.2 \mathrm{mg}$ of atropine and $10 \mathrm{mg}$ of ketamine. Temperature monitorization was also carried out in addition to standard monitorization. Deep sedation was achieved by administering $20 \mathrm{mg}$ of propofol and spontaneous respiration was maintained. The patient received no opioids or any other analgesics for perioperative analgesia. Patient was given oxygen with nasal cannula from $2 \mathrm{~L} / \mathrm{min}$. Hemodynamics and body temperature remained within normal limits. The intervention lasted ten minutes. There were eruptions with bleeding from the entrance of the esophagus during endoscopy. We did not observe any complications like nausea, vomiting and aspiration. He had no pain or fever at the postoperative period and was sent to the ward without any complication.

\section{Discussion}

Patients with CIPA require anesthesia implementations many times in their life due to self-mutilation as a result of the lack of sensitivity to pain. ${ }^{3}$ Although there is no pain sensation, patients have tactile hyperalgesia which is uncomfortable during the surgical procedure. Even though they will undergo minor surgery, they need anesthesia due to mental retardation and tactile hyperesthesia. ${ }^{3}$ Literature data suggests monitoring body temperature and stabilizing operating room's temperature at a constant level to avoid a probable hypothermia or hyperthermia which might be seen during anesthesia applications in

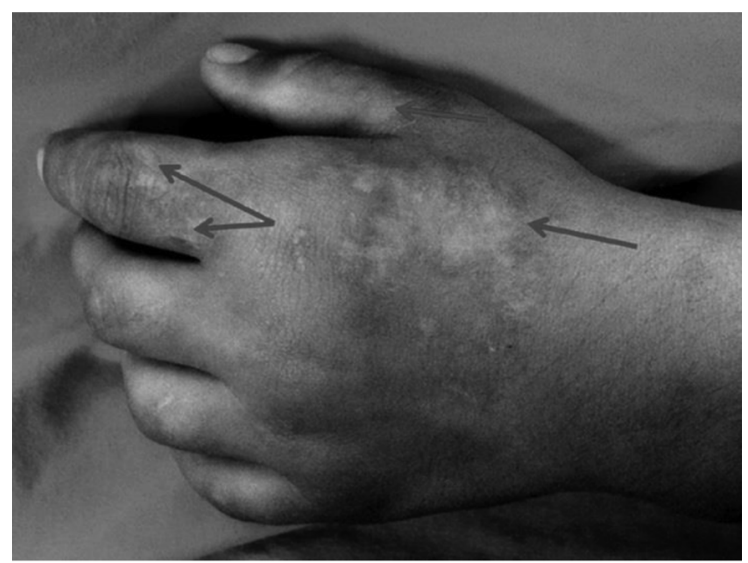

Fig. 1. Old burn scars in upper extremity. these patients. It has been reported that stress and anxiety may elevate body temperature and thus applying appropriate premedication is recommended. ${ }^{4}$ Even though there may be a relationship between the development of hyperthermia and the use of anticholinergic drugs in patients with CIPA in the literature, there are case reports showing safe usage of these agents without inducing hyperthermia. ${ }^{5}$ In our patient $0.2 \mathrm{mg}$ of atropine was used safely during the perioperative period without inducing hyperthermia. Although cardiovascular reflexes are preserved, patients with CIPA have reduced epinephrine and mostly norepinephrine levels. Cases with serious perioperative hypotension and bradycardia due to reduced catecholamine levels have been reported in the literature. ${ }^{4}$

There are case reports stating that gastric emptying is delayed in these patients due to autonomic dysfunction and therefore they suggest that rapid, serial endotracheal intubation and general anesthesia should be performed in these patients. ${ }^{6}$ As endoscopy is a short procedure and fasting period of the patient was adequate enough we planned the operation to be performed under sedation. Although endoscopy is a procedure that is strongly expected to provoke nausea and vomiting, we did not encounter any in contrast to the literature. According to our knowledge, this is the first case reported in the literature describing sedation for gastroscopy procedure in a patient diagnosed with CIPA.

Another problem in these patients during anesthesia is the difficulty in predicting the depth of anesthesia as a result of the reduction of the autonomic response to surgical stimuli. Bispectral index (BIS) is a significant monitorization which can reveal sedative and hypnotic effects of anesthetic drugs numerically. BIS shows the level of the depth of anesthesia and it is useful in determining the dose and timing of the anesthetic agents administered. ${ }^{7}$ We think that in this group of patients sufficient sedation should be provided, for procedural treatment even if they do not feel any pain. It is also better for this particular group of patients if sedation is performed with BIS monitoring during prolonged operations.

In conclusion, despite being rare, patients with CIPA represent a special population 
in which anesthesia management shows unique features. Because of the rarity of the disease, there is limited data regarding the safe anesthesia management in these patients. Therefore, we think that more clinical experience, case reports and studies are needed to clarify gastric emptying time, gastric $\mathrm{pH}$ and esophageal sphincter tonus in patients with CIPA to establish the appropriate anesthesia management.

\section{REFERENCES}

1. Weingarten TN, Sprung J, Ackerman JD, Bojanic K, Watson JC, Dyck PJ. Anesthesia and patients with congenital hyposensitivity to pain. Anesthesiology 2006; 105: 338-345.

2. Karımı M, Fallah R. A Case Report of Congenital Insensitivity to Pain and Anhidrosis (CIPA). Iran J Child Neurol 2012; 6: 45-48.
3. Conbay O, Kose EA, Celebi N, Karagoz AH, Ozgen S. Anesthesia for congenital intensitivity to pain with anhidrosis. Pediatr Anaesth 2007; 17: 190-192.

4. Tomioka T, Awaya Y, Nihei K, Sekiyama H, Sawamura S, Hanaoka K. Anesthesia for patients with congenital insensitivity to pain and anhidrosis: A questionnaire study in Japan. Anesth Analg 2002; 94: 271-274.

5. Okuda K, Arai T, Miwa T, Hiroki K. Anaesthetic management of children with congenital insensitivity to pain with anhidrosis. Paediatr Anaesth 2000; 10: 545-548.

6. Zlotnik A, Gruenbaum SE, Rozet I, Zhumadilov A, Shapira Y. A Risk of aspiration during anesthesia in patients with congenital insensitivity to pain with anhidrosis: case reports and review of the literature. J Anesth 2010; 24: 778-782.

7. Bali Ç, Bozdoğan Özyılkan N, Ergenoğlu P, Karslı A, Akın Ş. Konjenital ağrı duyarsızlığı olan bir olguda anestezi yönetimi. Anestezi Dergisi 2015; 23: 46-48. 